\title{
Formatting Cross-Media Circulation: On the Epistemology and Economy of Sports Highlights
}

To be published in: Format Matters, edited by Marek Jancovic, Alexandra Schneider, and Axel Volmar, Meson Press.

Markus Stauff, University of Amsterdam

m.stauff@uva.nl

In 1999 Elihu Katz argued for a more systematic development of a theory of diffusion: an interdisciplinary theory that could help to compare the spread of viruses, the circulation of goods and materials, the innovation of technologies and the adaptation and transformation of cultural values and meanings. The difficulty for such a theory, he argued then, results from the "ostensible incommensurability of diffusing items [and] their refusal to hold still in transit" (Katz 1999, 144). Media studies' recently surging interest in the concept of "format" (e.g., Moran 1998; Sterne 2012) can be considered a contribution to such a theory of diffusion; at least, the format's potential to enable diffusion by ordering content (or information) according to a material, technical, or legal framework is a shared concern of otherwise pretty heterogeneous approaches.

In the following, I take the omnipresence of sports highlights in media culture as a starting point to analyze the interrelation between formatting practices and cross-media circulation: Condensed representations of sports events featuring a number of selected moments and the result of a competition, arguably, belong to the most consistently and most dynamically circulating items in media culture for the last 100 years. Crossing all media (from film to television to online video and games), a number of different genres (news and entertainment), and often also the borders created by languages or nation states, sports highlights guarantee the "spreadability" (Jenkins, Ford, and Green 2013) of the results, narratives and mythologies of modern competitive sports.

Sports highlights don't show the same material rigidity or institutional consistency as more paradigmatic examples of formats - say a painting's physical frame or a sound file's technical and legal standards. But in offering selections and condensations of sports' special moments, they not only format - that is, standardize - observations on and knowledge about sport events, whether on film, television, or social media platforms, but also structure the very reality of sports. Simultaneously, these highlights, as with the formats of the TV industry (Magder 2004), allow for the constant modulation and local adaptation of content and form. This volatility gets harnessed and constrained through conflicting strategies of fans, rights holders, media platforms, and national governments, which all have a share in highlights' formatting potential. Thus, I want to argue that sports highlights' combination of standardization and flexibility makes it an especially rich example for a conceptual and empirical discussion of formats - or rather of formatting practices.

Taking my lead from television studies, I will argue that the sports highlight is a cultural technology of diffusion. Its cross-media circulation clearly results from a highly flexible but still regulated manner of transformation. This chapter, thus, aims to analyze how sports highlights travel because of a combination of epistemological, legal, and aesthetic strategies that result less in one particular format (with standardized characteristics) but rather in constantly adapting formatting practices. Sports becomes formatted into both an object of knowledge and a toolset for media industry; at the same time, the sports highlight provokes new industrial and legal strategies.

The first two sections of this chapter will sketch the historical and conceptual framework. First, I will describe how in the 19th century modern sports was made possible through representational forms that gave a reliable and condensed account of the 
competitions. Second, I will use the established notion of the TV format to specify some key characteristics of sports highlights as a format.

Thereafter, in the analytical part of this chapter, I will take a closer look at some of the dynamics that contribute to the recognizability and transformability of sports highlights. Each of the four sections of this second part focuses on one aspect of the actual work that highlights do, not only for sports but also for the media industries and media policy: (a) the sportshighlights compilation is a derivative format that achieves its identity from the task of condensing and circulating selected aspects of a competition; (b) its formal scalability and modularity allows the sports highlight to adapt this task to the requirements of different media and different cultural circumstances; (c) such flexibility extends its task, so that beyond the role of summarizing sports, the sports highlight becomes a tool to promote sport organizations and media industries; (d) because of its ambivalent status as both a derivative format and a valuable commodity, the sports highlight is harnessed for economic and political strategies.

\section{Historical Framing: Formatting Sports}

In the 19th century, the emergence of competitive spectator sports was made possible through condensed representations of its various events in the mass press. The reports on competitions from different places (and from different sports) created a public that got interested in a more comprehensive and more expansive comparison of performances. This interest, on the other hand, contributed to the serialization and standardization of sporting events (Werron 2014; 2010; 2009), a process that can itself be described as formatting: for example, instead of informal and spontaneous contests adapted to the given space and available time, horse races and running competitions became differentiated according to standardized lengths and ball games got framed by lines of fixed dimensions separating playing fields from spectators (Bale 1996).

This formatting of the sporting practices happens in close interrelationship with the formatting of the modes of observation and reporting. Most drastically, the result of a competition is condensed in a quantitative manner, as in the score of a football game (e.g., 31 ) and the places and finishing times of a horse race. Results of different events are aggregated in tables and rankings. Leagues, with their weekly changing tables, and World Records are two different, but nevertheless characteristic phenomena of the later 19th century. Both imply that performances that take place at different times and at different places can be compared, thanks to the standardization of the actual competition and of the way it is recorded and communicated (Heintz and Werron 2011, 276).

Next to results, rankings, and statistics, the condensed communication of sports events in newspapers and special-interest magazine harnessed narrative, allegorical, and pictorial modes of observation, too, which embellished and contextualized the sober quantitative formatting of individual events. This implies the selection of distinctive moments from a competition that are considered either to have led to the result or to be remarkable independent of that result. In both cases, the mere result is supplemented with representations of what are considered the highlights of the event (Gamache 2010). A goal scored in a team sport and crossing the finish line in a race are both clear examples of the results-oriented aspect of highlights; yet especially artful or skilled movements can become part of highlights compilations too, as can controversial referee decisions or eventually any athlete's (or even audience member's) remarkable, especially fair or unfair, spectacular or dumb behavior. While there are clear cornerstones for sports highlights, they always leave room for more subjective impression and therefore open a discussion about the most appropriate way of condensing an event. 
While sports highlights mainly are conceived of as representations in hindsight of the event, they were quickly also contributing to the expectations for upcoming competitions. Characteristically, reporting on the 1908 Olympic Games in London announced the marathon race two days in advance, singling out stretches of the course expected to create especially exciting moments or considered to be advantageous or disadvantageous for particular types of athletes (Stauff 2018a).

To wrap up this short historical introduction, highlights have an epistemological function. They serve as formats to observe, select, define, and organize, but also to question or debate, the moments of an event considered to be relevant, memorable, and spreadable. As with most formats, highlights compilations often aggregate sub-formats; they include results, statistics, tables, and highly formatted narratives. Sports highlights result from the intersection of two interrelated formatting processes. They are defined partly by the format of each sport, its dramaturgy and rules, and partly by the formatted modes of observation. A decisive move or particular turn of events becomes a highlight when it can be condensed into a recognizable and repeatable representation, which is as much dependent on the rules of the sport as on the forms and technologies harnessed to give an account of a competition. Modern competitive sports only exist because of formats that shape their observation and provoke a selection of key moments that can easily be circulated. The diffusion is stimulated by effective condensations that harness different media forms (numbers, narratives, images) and therefore allow for easy adaptation to different media systems (press, film, television). The ongoing debate about whether the most important moments are selected and if the mode of representation is appropriate further spurs the diffusion process.

Before I go into detail about the dynamics that contribute to the formatting function of highlights, I will first offer some more conceptual remarks concerning the notion of format. Taking my lead from television studies, I argue that the concept of format is intriguing because it allows one to describe a highly flexible but still regulated manner of transformation.

\section{Conceptual Framing: Form/Format/TV Format}

The sports highlight, I argued in the first section, fosters the diffusion of sports' remarkable events and results. Thus, it has close affinities to the concept of format, given that formats can be defined as modes of presentation that are made to enable and facilitate certain modes of circulation. ${ }^{1}$ As Gerard Genette explains in Paratexts, the format of a book (originally resulting from folding the paper in different manners) is one of the earliest uses of the term; the format materially shapes mobility and moreover connotes a certain position on the ladder of cultural respectability — as we know especially from paperbacks or "pocket editions" (Genette 1997, 18).

Since the sports highlight misses the clear material delineation characterizing the different book formats (or technical formats like MP3), it might seem likely to describe it as a genre or even more general as a form. Caroline Levine (2016), at least, has convincingly argued that forms order signs, materialities, and meanings in a restraining and recognizable manner. The most basic result hereof is that forms differ: it is often easy to distinguish one form from another. Additionally, this allows forms to travel. They move across different

\footnotetext{
${ }^{1}$ According to Lothar Mikos, formats are modes of presentation ("Präsentationsformen") that adapt to media's capabilities to show and tell; thereby, he contrasts formats with genres' function of ordering content according to patterns of cultural meaning (Mikos 1995, 170). For a similar distinction between format and genre, though focusing more on the trade aspect, see Keane and Moran $(2008,158)$.
} 
materials and media, across different cultures and regions, and not least between media representations (or art, if you like) on the one hand and social reality on the other (Levine 2016, 4-7).

The concept of format, however, highlights how some forms are more closely bound to a set of practices and an institutional context than others. Understanding highlights as format (and not merely as form or genre), thus allows one to underline their specific function for the institutional system of sports media and the implicit and explicit regulations of highlight compilations that come with that (and which will be outlined in the following sections).

A format is connected to a series of decisions and a set of explicit rules that have to be followed to make it work for a particular medium and to intentionally foster the circulation process. Liam Young $(2017,38)$, for example, argues that the list is a form in the context of art practices (the famous lists of Homer) but a format in the context of administration because it is used to fulfil explicit tasks and gains a particular epistemological function. The making of the list and its circulation is shaped by patterned practices and institutional concerns. While Young bases his reflections on the format mainly on Jonathan Sterne's (2012) analysis of the MP3, I will refer here to the notion of format in the television industry and television studies. Sterne's work on the MP3 approaches the format as a "crystallized set of social and material relations" $(2006,826)$ that inscribes certain assumptions about human listening into a technical standard $(2012,2)$. The TV format, with its focus on adaptability to different contexts, rather multiplies than crystallizes and thus seems the more fitting model for sports highlights' cross-media mutations - not least because sports-highlights compilations, even if emphatically cross-media, developed most explosively in the context of television.

For a long time, TV formats were mostly agents of standardization and crystallization, too. The program schedule establishes a grid of predefined segments of 30 or 60 minutes and additionally establishes an intricate entanglement of specific positions in the grid with allegedly appropriate content and values. The differences between daytime and prime-time programming and between weekday and weekend programming are the most conspicuous formatting dynamics here. Additionally, the enormous technical and organizational investment necessitated by broadcasting led to the establishment of basic routines of content production that shaped the standardized setup of cameras and lighting, editing, and modes of address. Live studio production and live-on-tape production, but also outdoor live events with huge trucks and kilometers of cable, can all be considered patterned production practices that become applied to varying content.

A somewhat different concept of format developed in the context of global program exchange which is much facilitated by the licensing of content, or rather ideas and concepts that can be multiplied and adapted to different contexts. Such TV formats had been around since the 1950s, but only emerged as a dominant tool for the distribution of TV content with the globalization and nonlinearization of the TV industry in the 1990s (Moran 2009). Until then, international program exchange was dominated by so-called "canned programs" (e.g., Waisbord 2004) in which programs were sold and distributed on celluloid or video tape and adapted slightly at times to the local context through the addition of subtitles, dubbing, or some re-editing. As an answer to the growing demand for new, cheap, and low-risk content, however, companies in the 1990s started to sell programming templates, which enabled the production of local and seasonal variants of already successful programs. While first mainly applied to quiz and game shows and reality programs, it by now has become a tool for the circulation of scripted content as well (Chalaby 2016).

The format, here, is first of all a manual for producing not only multiple episodes of a program but also different national variations based on a formula that has proven its success and allows for flexible scaling to available budgets (Moran 1998; 2009). Instead of a "canned program," customers receive a so-called "paper format," which outlines key aesthetic 
elements and provides guidelines for the production and marketing "that can be tailored to each locale" (Magder 2004, 147). According to Silvio Waisbord (2004), the format thus "bridges transnational economic interests and national sentiments of belonging" (368). Big Brother might be the most famous example. As of November 2018, Wikipedia announces, "there have been 445 seasons of Big Brother in over 54 franchise countries and regions" ("Big Brother (Franchise)" 2018). Additionally, when formats travel, it sometimes is less the textual form that is exchanged than knowledge about the organizational and technological ways of running a show, thus fostering particular forms of craftsmanship as well as industrialized, factory-like productions and their local adaptations (Keinonen 2017).

Canned programs and paper formats imply a different way of organizing production, different systems of distribution, and specific concepts of the audience (Moran 2009). In the case of canned programs, the formatting takes places in the production process and circulates as stable text and as material technology (a tape, a file, etc.). In the case of paper formats, it is rather contractual regulations, format information, and know-how "in the shape of a set of services designed to help in the production of the program elsewhere" (Moran 2009, 17). Characteristically, TV formats, while allowing for the flexible adaptation of content to local contexts, emerged together with a new global system of trade comprising, among other things, interdependent economic agents, global institutions, and copyright rules (Chalaby 2015). In this sense, TV formats clearly shaped the infrastructure they circulate on.

The TV format presents an interesting example for diffusion theory because what travels is not a thing or a recognizable form that is placed in different contexts. What circulates are composites of forms, practices, materials, and regulations that enable the generation and reconstruction of a number of versions. Much more flexible than the canned program, the TV format can be considered a "cultural technology" that "governs the flow of program ideas across time and space" (Moran 1998, 23). It functions as a generative matrix, regulating formal innovation and the cross-cultural travel of ideas, narratives, technologies, and economic strategies. In the following sections, I will build on that to analyze how sports highlight compilations work as a generative matrix that organizes diffusion across different media through practices of formatting.

\section{Selection/Condensation: Highlights as Operational Forms}

To a certain extent, sports-highlights compilations are a forerunner of the TV format. Since the 1950s, mega events like the Olympics or World Cup have sold media access to sports competitions and provided rules (a proto paper format) outlining how broadcasters are allowed to adapt the content to their national interests. Unlike TV formats, though, most sports highlights are not defined by a template or a program bible. In contrast to a paper format that is sold, adapted, and modulated for different seasons and countries, sports highlights are a much more elusive entity. Yet Albert Moran (1998) helpfully clarifies: "The term [format] has meaning not so much because of what it is, but rather because of what it permits or facilitates" (18). And as composites of forms, practices, materials, and regulations, sports highlights, I argue, can be considered formats because of the work that they do. Similarly to the TV format, they allow for flexible but patterned adaptation to different contexts and especially to different media and related social practices. I want to use the remainder of this paper to discuss how sports highlights govern the flow of images and ideas across time and space due to a particular overlap of formal conventions, technological innovations, economic strategies, and legal dynamics.

As I outlined in the historical framing at the start of this paper, a first aspect of the formatting work that sports-highlights compilations perform is the "creation of a visual 
shorthand" for decisive, telling, and thrilling moments of a competition "through the use of condensation and remediation" (Gamache 2010,10). A certain formal stability results from this operational aspect of the highlights: they have to give an account of why and how one side won the contest while the other lost. The formal conventions at least partly depend on the rules, the temporal and spatial characteristics of specific sports.

During the 19th century, narrative reports in the press, maybe augmented by numbers, drawings, or photographs, contributed to the development of what one might call a highlight sensibility. Rudimentary forms of sports-highlights compilations also existed from the start of cinema in the 1890s. Dan Streible's (2008) history of the early boxing film shows that for quite a while, the distinction between highlights and full-event coverage was less systematic than dependent on technical capabilities, spontaneous practices, and legal disputes. Early cinema often displayed boxing as an attraction without aiming to present an actual competition; if actual competitions (or re-enactments of them) were staged to be filmed, they became adapted to the medium, such as by having rounds of only one minute to fit the length of a film reel (Streible 2008, 6). When kinetoscope parlors presented the individual rounds of a fight in separate kinetoscopes, often the audience turned out to watch the knockout round only (Gamache 2010, 20).

With consolidation of the institutional and technological settings of cinema, highlights compilations eventually achieved a conventionalized form, as Raymond Gamache (2010) details in his comprehensive A History of Sports Highlights. Not least because of sports' regular schedule throughout the year, highlights quickly became a staple of newsreels in the early 1910s and thereby emerged as the dominant framework for presenting sports as a separate segment of news. The newsreel highlights contributed to the familiarization of a broad audience with American football and other sports (Gamache 2010, 4). Just like magazine formats on television in the 1950s (like BBC's Match of the Day and Grandstand), they made sports accessible to a broader, nonexpert audience (Whannel 1991) and thereby also diffused sports' racial and gender hierarchies into common culture (Gamache 2010, 67).

The conventionalized form typically presented a "composite story of a sporting event comprised of multiple parts" (Gamache 2010, 39); it started with the venue and the presentation of teams, included a selection of highlight moments and shots of the audience reacting, and ended with images of the winners' celebration. When film sound was available in the late 1920s, the commentators fostered a more individualizing perspective, adding personal stories (Gamache 2010, 51).

In the 1940s, when television started, sports-highlights compilations soon became part of the schedule too. "While the delivery systems of sportscast highlights have changed, what has not undergone significant change is the highlight form itself" (Gamache 2010, 10). With new technology, close ups, slow-motion replays, and data visualizations were successively integrated into an overall pretty stable form as specific but complimentary means to do the work of selection and condensation, evaluation and admiration.

It speaks to the stability of the format and its function that most sports computer games present a selection of highlights after each game played, which follow pretty much the formal pattern established in film and television throughout the past 100 years. Not surprisingly, experiments in computer-based video analytics have come up with several models for the automated detection of highlights in television footage (e.g., Radhakrishnan et al. 2005; Hao Tang et al. 2011; Assfalg et al. 2003).

Nevertheless, as I will argue in the following section, the formatting work of highlights results first of all from the scalability and adaptability of this otherwise recognizable form. On the one hand, sports highlights easily integrate heterogeneous media; the formatting work thus results less from the form or materiality of a particular medium than from a more general endeavor to diffuse sports through efficient (if controversial) selection and condensation of key moments. On the other hand, the work sports-highlights compilations 
do also comprises the flexible formatting of selection and condensation according to different media infrastructures and cultural contexts.

\section{Scalability/Modularity: Adapting to Media and Cultural Contexts}

Interestingly, Gamache (2010, 49-66) describes the patterns in the history of sports highlights as resulting from habits, just as Magder (2004) in his discussion of format states that the day-to-day business of television "runs on habit" (143). Recent discussion of the concept has underlined the generative potential of habits: instead of blindly and automatedly executing the same actions, habits, this research argues, function as modes of embodied thinking that allow behaviors to adapt to changing environments (Bennett 2016; Grosz 2013). Taking my lead from such a perspective, I want to argue that the ostensive formal simplicity of sports highlights, resulting from the half-automated operation of selecting and condensing the decisive and remarkable moments, allows for ist adaption to different temporal and infrastructural circumstances.

First of all, the formatting work of highlights-compilations becomes visible in their intense scalability. ${ }^{2}$ They allow for a very flexible transition between the full event and the highly condensed representation of the mere result. This transition is possible because of the highlights' flexible combination of different media forms like numbers, lists, spectacular images, and overarching narratives. In games that consist of a series of distinct moves, such as baseball and billiards, every single action could be documented even before the invention of moving image technology. In 1881, Vienna's Allgemeine Sportzeitung, for instance, noted down every single strike of a game of pool in a table full of numbers, providing a very condensed representation of the full event without actually determining its highlights (Allgemeine Sport-Zeitung 1881).

The more common practice in today's media landscape is a live transmission of events in which commentators and the use of replays already clearly signal relevant or remarkable highlights. Directly after the game, these highlights become part of a post-game show in which athletes and experts comment on isolated moments to further evaluate their significance. A more strictly and coherently narrativized compilation of highlights occurs in shows that summarize entire game days in retrospect (like the British Grandstand, or the German Sportschau). Shorter versions of these are often presented at the end of news programs or increasingly on the apps of broadcasters and sports organizations, such as the National Football League (NFL) and National Basketball Association (NBA) in the United States, and their media partners, such as Facebook and YouTube.

In Germany, for example, the evening news program of public service broadcaster ARD, Tagesschau, presents condensed highlights of some games just 15 minutes after the longer versions of these compilations have been presented in the Sportschau on the same channel. About two hours later, the competing public service broadcaster ZDF also summarizes the game day, but unlike the rather sober and linear highlight reels of the Sportschau, these focus on more idiosyncratic aspects of the matches (the development of a young talent, the fate of a coach, the relationship of a club with its fans, and so on).

The number of remarkable moments, their formal treatment, and their recontextualization can easily be modified. Sports highlights can thus be molded to fit timing from the original event, audience prior knowledge, cultural and national context, and strategic industrial and institutional function.

\footnotetext{
${ }^{2}$ On the epistemological and methodological implications of scaling, see McCarthy (2006).
} 
This can be illustrated by means of a very well-known example. The 1966 men's World Cup final between England and Germany was represented in condensed form by newspapers and magazines, on television, and in movie theaters. Already the number of cameras at the event allowed for varying presentations of the same highlight moments (next to the TV cameras were film cameras recording in black and white and in color). Additionally, the game included one especially controversial moment: a shot by the English team that bounced from the crossbar down to the goal line and from there back into the field, which was called a goal by the referee. This moment became a point of focus in later highlight reels of the game and provoked a proliferation of re-contextualization and forensic scrutiny (Stauff $2018 \mathrm{~b}$ ), with, of course, opposing national narratives. The contemporary newsreel in German cinemas - the Fox Tönende Wochenschau - announced the scene as "the most controversial goal of the tournament" and showed it from two different camera angles. The second was presented in slow motion with the commentary stating, "these images prove that it was not a goal." 3

Forty years later this moment was included in a DVD with highlights from BBC's Match of the Day (BBC Match of the Day 2004) and in a DVD celebrating 100 years of FIFA (FIFA Fever 2002). On the FIFA DVD, the controversial goal is actually presented twice, first in the chapter on controversial World Cup decisions, where it becomes part of a series of similar situations that all are isolated from their original context, and then a second time in a special chapter on Germany's World Cup successes. There, the goal is supplemented by an interview with one of the German players from 1966, claiming that it was a bad call by the referee but that the sportsmanlike manner in which his team accepted the decision advanced Germany's global reputation. This is only included in the German version of the DVD, of course; on the international Special Deluxe Edition of FIFA Fever (2002), the summary of the game is wrapped up with praise for Geoff Hurst's hat trick in the game and with images of the English players celebrating, the voice-over stating, "Now the nation could rejoice."

The formatting work of highlights, scaling and adapting sports' special moments to different contexts and requirements, takes advantage of the rich mediatization of sports. Often many different media capture alternative versions of special moments, which can also be accounted for through more indirect means of representation: depictions of scoreboards in the stadium or of the audience cheering; testimonies of participants and eye-witnesses; and graphics, reenactments, and computer simulations. All of these exist for the 1966 goal. As a consequence, sports highlights are highly modular: images, sounds, voice-over, and additional footage can easily be replaced, augmented, and reedited. This makes "localization"-TVformats' characteristic adaptability to cultural contexts and national broadcasters' needs (e.g. Chalaby 2005) — easily possible.

As I will show in the final two sections, the sports highlights' combination of condensation and scalability makes it both a productive machinery for managing reputation and attention and a well-protected yet contested commodity. Its formatting work allows sports to circulate across media, but it also allows for industrial and political strategies that harness sports through the formatting potential of highlights.

\section{Promoting Sports/Managing Attention: Highlights as Cross-Media}

\section{Strategy}

The re-mediation and formal adaptation of sports highlights is shaped and fostered not only by the work they do for sports but just as much by the work they do for the media

\footnotetext{
${ }^{3}$ My translation.
} 
industries. Their modularity and scalability make highlights into versatile, strategically harvested instruments in the attention economy.

Because highlights condense and collect special moments that can easily be de- and recontextualized, they are open for additional layers of meaning, beyond the communication and evaluation of athletic performances. Gamache argues that already in the 1920s and 30s the newsreels "helped to establish athletes as the heroes and heroines of a burgeoning consumer culture, comparable in stature to the Hollywood movie actors that followed the athletes onto the screen" (Gamache 2010,67). The fragmentation of a game into outstanding moments, presented in slow-motion replays, fostered the connection between individual athletes and commodities or brands, which (more often than not) were based on a hegemonic concept of masculinity (Morse 1983) that is even more pronounced in highlight reels than in the coverage of entire games with all their contingencies. Later, highlights were key for the emergence of global megastars like Michael Jordan, Wayne Gretsky, and David Beckham, who had impacts far beyond their respective sports (Gamache 2010,7).

The taming of contingency, as well as the modularity that allows for the aggregation of topical situations and their embellishment with music and voice-over, makes the highlight an ideal tool to establish a cultural identity for a particular sport or a sports organization (Gamache 2010, 10). Most famously, the American professional football league, the NFL, already in 1964 established a subsidiary film production company NFL Films. Travis Vogan has shown in detail how the careful selection, curation, editing, and embellishment of highlights, realized by NFL Films on a comprehensive scale for decades, shaped the cultural memory, meaning, and affectivity of the sport, making "pro football into a spectacle that exceeds its position as a sports organization and becomes a corporate site of cultural production" (Vogan 2014). Needless to say, highlights, far from being limited to summarizing competitions in hindsight, have thus also themselves become commercials announcing and creating expectations for upcoming events.

Next to this general commercial work for the wider sports and cultural industry, the scalability and modularity of highlights allows them to do invaluable "convergence work." Format TV, like Big Brother, Survivor, or Idols, not only enable global flows of content ideas but also organize - through online quizzes, additional backstage footage, and the like - the herding of audience attention across different media platforms (Bignell 2005; Ouellette and Wilson 2011).

Similarly, sports highlights are a key tool, as Victoria Johnson (2009) has shown, for the implementation of new media technologies and for their entanglement with the traditional media industries. They foster a smooth transition from the liveness economy of broadcast media to the access and click economy of social media; they can be fragmented, parceled, deand recontextualized. This enables traditional media companies to expand to online culture where they can offer extra highlight reels. Additionally, it allows social media companies to harness sports to create buzz and clicks. Nowadays, Twitter, Facebook, YouTube, and other social media giants are in competition to win contracts with the major sport leagues and the "sport mega events" (like the Olympics and World Cups) for posting highlights. On Twitter, sponsored highlights are posted while a game is still ongoing (Kantrowitz 2018).

Sports highlights allow for connecting and bridging different media while pointing out their differences, and they combine watching (mass audience) with participation (individual users). The often unanimous agreement on what are the decisive (or awe-inspiring) moments of a game combined with the structural disagreement concerning the evaluation of a situation guarantee a stable core for the frantic multiplication and variation of sports highlights. The work of giving an account of events through selection and condensation and the work of scaling and adapting to different historical, cultural, and technological circumstances are closely interdependent. This makes the sports highlights also one of the prevalent formats of user generated content and on social media platforms more generally. Spawned by (and 
overlapping with) the success of lists and rankings online, sports highlights get de- and recontextualized into compilations, such as "Top 33 Unexpected Goals in Football" (2018), "Top 100 Goals Scored by Legendary Football Players" (2018), and "Best Humiliating Goals 2019" (2018) — not so different from what the FIFA Fever DVD already offered in 2002.

Against this background one can conceive of sports highlights not only as TV formats but also as memes avant-la-lettre. In 1976 Richard Dawkins used the concept to describe cultural units that are easily and reliably copied; the actual online memes-somewhat contrary to Dawkins original definition - circulate not because of identical reproduction but because of certain patterns of transformation that appropriate the differences of media and the tension between isolation and re-contexualization (Shifman 2013). Similar to sports highlights, memes are often based on a recognizable form (e.g., the image macros), but their circulation dynamic results from modularity and adaptability. Contrary to memes, however, which are shaped by a click-economy, sports highlights owe their quality as formats mainly to a copyright-based economy. Sports highlights' formatting potential allows for and is intensified through their appropriation as industrial strategies. They offer a machinery to adapt the form to different media and different commercial strategies. Their formatting of diffusion is inseparable from their dual character as property and public good.

\section{Protection and Obligation: Highlights as Contested Commodity}

The power of sports highlights to herd audiences and organize attention across different media makes them a valuable commodity. As I will show in this final section, it is a highly contested and therefore conceptually ambivalent commodity. The surge of TV formats introduced a new form of commodity, whose legal status remains vague because in most countries a "program idea"- the "paper format"-is not protected by copyright law. The sports highlight, as a derivative format that summarizes an original event to foster its diffusion, is even fuzzier as a commodity. Contracts and laws struggle in formatting the highlights into an economically and politically efficient entity. As is often the case with sports, though, the ongoing technical transformation also provokes ongoing renegotiations of what sports highlights are and who is allowed to use them in which way. The formatting potential of highlights, the way they condense and diffuse sports, is closely interrelated with ongoing conflicts about access to events and the reuse of event coverage.

When filmic documentation of boxing first became a commercial success in the later 1890 s, the organizers started to sell exclusive rights to film producers. Already then, competitors tried to smuggle in cameras to "pirate" the events (Streible 2008, 106-108). Over the following decades, with varying patterns in different countries and for different sports, it became increasingly common for film companies (and later TV broadcasters) to be charged for access to major sports events. ${ }^{4}$ In the case of the Olympics, for example, the local organizers of the London games in 1908 were the first to grant exclusive filming rights to one company; the organizers of the 1928 games in Amsterdam created outrage for selling the rights to an Italian producer, who offered a better deal than the Dutch companies (McKernan 2011); the BBC was the first TV broadcaster to pay a small allowance for the 1948 London games.

For Olympic highlights, though, the 1956 Melbourne games became a watershed moment. For the first time, the IOC asked for $\$ 500,000$ from the US networks for

\footnotetext{
${ }^{4}$ In the 1920s, for example, "[i]n England, companies routinely paid for the rights to film important sporting events; however, securing the rights to an event of public importance was not common practice in America." (Gamache 2010, 62) Until today, some minor sports pay TV stations to broadcast their events to create attention.
} 
broadcasting the event. As a consequence, media from all over the world threatened to boycott the games (Gajek 2013, 322). The press, after all, was granted free access because sports organizers knew very well that without press coverage few people would be interested in sporting events. The filming of events, however, and their transmission via radio and TV was considered to be a replacement for the real event that might trigger a decrease in actual visitors. In this context, highlight reporting had an ambivalent status: film and TV companies, not least with reference to sports' widespread coverage in newsreels, argued that sports highlights would be news, even more so because the Olympic Games (more than the commercial exploits of US baseball or boxing) were considered events of general public interest.

This conflict led to a formal recognition of the specific legal and economic status of highlights, when the IOC, in its official Olympic Rules, replaced an older paragraph on "Photographs and Films" with a newer, much longer one on "Publicity." Alongside granting free access to staff from the press, movies, radio and television, the local Organizing Committee was now explicitly tasked with both selling the "Live Television Rights" and providing newsreels for general circulation. For broadcasters that did not pay for live transmission rights, however, the use of this newsreel footage was highly specified:

Newsreel showing, whether cinema or television, shall be limited to regularly scheduled shows, where news is the essence of the program, of networks or individual stations. No individual program may use more than 3 minutes of Olympic footage a day. No network, television station or cinema may use more than three sections of three minutes of Olympic footage in all news programs combined within twenty-four hours, and there shall be at least four hours between each showing. In no case can these newsreel films be used for the compilation of any kind of special. (International Olympic Committee 1958, §49)

The granting of highlights without charge was less a concession to "public interest" than an acknowledgment of the work highlights do in creating a public that is interested in the ongoing evaluation and admiration of sports performances. From 1930 on, the IOC obliged the local organizers to "make the necessary arrangements for making a record of the Games by means of photography and moving pictures" (International Olympic Committee 1930, 30).

Maybe even more tellingly for the indispensable function of highlights, until today broadcasters that pay for the live transmission of an event are bound by contract to include summaries in their schedules too. For the 2014 World Cup, for example, the rights holders were "obligated to provide a roundup program that lasted at least 30 minutes and included daily highlights of the World Cup" (Rampazzo Gambarato et al. 2017, 285).

With the success of social media platforms, the ambivalent status of highlights as prized commodity and promotional tool only became more pronounced. Often, user-generated highlight films are taken down because of the infringement of intellectual property rights. ${ }^{5}$ There are other occasions, though, when fan contributions (infringement notwithstanding) are tolerated or even encouraged because of their potential to attract a broader audience (Corrigan 2014, 48). While the NFL forced Twitter to suspend the accounts of reputable publications because they posted highlight videos there, the NBA has accepted fan highlight channels on YouTube considering them as marketing (Winkie 2016).

Because of their potential to create a public different from the audience of the live event, sports highlights additionally became objects of political and legal concerns. In the context of the establishment of commercial broadcasters and their Pay TV channels in

\footnotetext{
${ }^{5}$ This quite probably happens to the YouTube videos I referenced above. They are quickly replaced though by similar compilations with very similar titles.
} 
Europe, for example, the appeal of sports highlights was supposed to ensure that issues of public and national concern would be accessible to wide audiences (and for public service broadcasters). In 1991 Germany augmented its broadcast law with a paragraph regulating the right of news and highlights coverage, the so-called "Kurzberichterstattungsrecht," which was later implemented on the European level too. In the current installment, this law, more flexibly than the IOC's, determines the acceptable lengths of highlights compilations as being dependent on the duration necessary to cover the news-related aspects of the event, which, generally, are supposed to be no longer than 1.5 minutes ("Staatsvertrag Für Rundfunk Und Telemedien” 2016, §5).

The rationale behind the new paragraph, which covered all kinds of events and news, was to prevent against football being covered only by commercial stations. Sports highlights have thus become a format meant to guarantee the diffusion of content across the public service-commercial divide. Additionally, sports highlights are used to create competition on the otherwise monopolistic market for sports rights. In the 2000s, the European Commission forced the German football league to split the rights into nine packages.

The packages include: two live rights packages, available to free-to-air and pay broadcasters; three highlights packages, two of which must be on free-to-air, including one that contains the rights for a minimum of two live matches a season; one live internet rights package; and one live or near live package of mobile phone rights. (Gratton and Solberg 2007, 161)

These are only more or less random examples. Each league, country, sports event, broadcaster, and platform develops its own highlights strategy. The cases discussed here might suffice to show how the diffusion potential of sports highlights is intensely shaped byoften conflicting - legal and economic practices that, at the same time, have constantly been adapted to the transformative potential of highlights over the past 100 years.

\section{Conclusion}

This article has shown that sports highlights are a relevant example for a general theory of cultural diffusion. They transform the events of sports into a highly spreadable form. They do this, first, through a process of selection and condensation that aims at compiling the most decisive and spectacular moments in a comprehensive and appropriate manner-their epistemological function. Second, highlights enable circulation by offering this compilation in a scalable and modular way, that allows for adaptation to different technological and cultural circumstances; that they "refuse to hold still in transit" (Katz 1999, 144) accommodates the ongoing debates about the appropriate evaluation of performances that have characterized sports culture for more than a century. However, highlights do not circulate because of what they do for sports culture alone; rather, their diffusion is fostered through industrial and political strategies that harness the scalability of highlights also to scale up audiences and manage their attention. The volatility of highlights becomes an economic and legal concern and is thus connected to a number of different dynamics.

Understanding the sports highlight as a format thus forces us to pay attention to the uneven entanglement of textual elements, technologies, regulations, and practices. Formats govern the circulation of culture by combining a number of heterogeneous elements that undergo dynamic, yet patterned, transformation in their adaptation to different media systems and cultural contexts. Importantly, formats negotiate the relationship between the circulating content and the infrastructure it circulates in. Sterne (2012) conceives of infrastructure as the 
water "in which the MP3 fish swim" (15); in this context, sports highlights, rather amphibian, move between water and land, provoking changes in the coastal line. The constitutive transformability of sports highlights allows for integration of and adaptation to different media technologies and media industries; simultaneously, the technologies and industries are entangled with the volatile formats and thus undergo change themselves.

The sports highlight is not just a standardized form to account for the results of sports but also contributes to the formatting of sporting practices. Similarly, as sports highlights adapt to different media infrastructures, such as film newsreels, television, and online meme culture, they shape the industrial, technical, and legal environment. Sports highlights are a format that allows for certain modulations and contributes to the formatting of reality, but they also become formatted through strategies that aim to constrain and harness their volatility.

As an admittedly marginal example of a format, finally, the sports highlights could direct the attention of format studies toward patterned flexibility as a key aspect of format productivity. While formats are often understood as forms geared toward one specific infrastructure or the creation of compatibility, it might be worth analyzing how formats structure the transformative and mutual adaptation of content and infrastructures.

\section{References}

Allgemeine Sport-Zeitung. 1881. "Das Große Wiener Billard-Turnier,” January 27.

Assfalg, Jürgen, Marco Bertini, Carlo Colombo, Alberto Del Bimbo, and Walter Nunziati. 2003. "Semantic Annotation of Soccer Videos: Automatic Highlights Identification." Computer Vision and Image Understanding 92 (2-3): 285-305. https://doi.org/10.1016/j.cviu.2003.06.004.

Bale, John. 1996. Landscapes of Modern Sport. London: Leicester University Press.

BBC Match of the Day: The Best of the 60s, 70s and 80s. 2004. DVD. Produced by Ian Finch, Niall Sloane, Paul Armstrong, and Phil Bigwood. London: 2 Entertain Video.

Bennett, Tony. 2016. "Mind the Gap: Toward a Political History of Habit." The Comparatist 40 (1): 28-55. https://doi.org/10.1353/com.2016.0002.

"Best Humiliating Goals 2019" 2018. YouTube video, posted by "Shatta Wale," published on December 22. https://www.youtube.com/watch? $\mathrm{v}=\mathrm{i}$ OrymXLIjuM.

"Big Brother (Franchise)." 2018. Wikipedia. July 23, 2018. https://en.wikipedia.org/w/index.php?title=Big_Brother_(franchise)\&oldid=85161184 0 .

Bignell, Jonathan. 2005. Big Brother: Reality TV in the Twenty-First Century. Basingstoke, UK, and New York: Palgrave Macmillan.

Chalaby, Jean K., ed. 2005. Transnational Television Worldwide: Towards a New Media Order. London and New York: I.B. Tauris.

. 2015. "The Advent of the Transnational TV Format Trading System: A Global Commodity Chain Analysis." Media, Culture \& Society 37 (3): 460-478.

— 2016. "Drama without Drama: The Late Rise of Scripted TV Formats." Television \& New Media 17 (1): 3-20.

Corrigan, Thomas F. 2014. "The Political Economy of Sports and New Media." In Routledge Handbook of Sport and New Media, edited by Andrew C. Billings, 43-54. London and New York: Routledge.

FIFA Fever: Celebrating 100 Years of FIFA. 2002. DVD. TWI/FIFA.

FIFA Fever: Celebrating 100 Years of FIFA. Special Deluxe Edition. 2002. DVD. TWI/FIFA. 
Gajek, Eva Maria. 2013. Imagepolitik im Olympischen Wettstreit: Die Spiele von Rom 1960 und München 1972. Geschichte der Gegenwart, Bd. 7. Göttingen: Wallstein.

Gamache, Raymond. 2010. A History of Sports Highlights: Replayed Plays from Edison to $E S P N$. Jefferson, NC: McFarland.

Genette, Gérard. 1997. Paratexts: Thresholds of Interpretation. Translated by Jane E. Lewin. Cambridge and New York: Cambridge University Press.

Gratton, Chris, and Harry Arne Solberg. 2007. The Economics of Sports Broadcasting. London and New York: Routledge.

Grosz, Elizabeth. 2013. "Habit Today: Ravaisson, Bergson, Deleuze and Us." Body \& Society 19 (2-3): 217-39. https://doi.org/10.1177/1357034X12472544.

Hao Tang, Vivek Kwatra, Mehmet Emre Sargin, and Ullas Gargi. 2011. "Detecting Highlights in Sports Videos: Cricket as a Test Case." In Proceedings of the 2011 IEEE International Conference on Multimedia and Expo, 1-6. https://doi.org/10.1109/ICME.2011.6012139.

Heintz, Bettina, and Tobias Werron. 2011. "Wie ist Globalisierung möglich? Zur Entstehung globaler Vergleichshorizonte am Beispiel von Wissenschaft und Sport.” KZfSS Kölner Zeitschrift für Soziologie und Sozialpsychologie 63 (3): 359-94. https://doi.org/10.1007/s11577-011-0142-5.

International Olympic Committee. 1930. "Charte Des Jeux Olympiques." https://www.olympic.org/olympic-studies-centre/collections/officialpublications/olympic-charters. 1958. "The Olympic Games. Fundamental Principles, Rules and Regulations. General Information." https://www.olympic.org/olympic-studiescentre/collections/official-publications/olympic-charters.

Jenkins, Henry, Sam Ford, and Joshua Green. 2013. Spreadable Media. Creating Value and Meaning in a Networked Culture. New York: New York University Press.

Johnson, Victoria E. 2009. "Everything New Is Old Again. Sport Television, Innovation and Tradition for a Multi-Platform Era." In Beyond Prime Time: Television Programming in the Post-Network Era, edited by Amanda D Lotz, 114-137. London: Routledge.

Kantrowitz, Alex. 2018. "How Twitter Made the Tech World's Most Unlikely Comeback." BuzzFeed News, June 21, 2018.

https://www.buzzfeednews.com/article/alexkantrowitz/how-twitter-made-the-techworlds-most-unlikely-comeback.

Katz, Elihu. 1999. "Theorizing Diffusion: Tarde and Sorokin Revisited." The Annals of the American Academy of Political and Social Science 566 (1): 144-55. https://doi.org/10.1177/000271629956600112.

Keane, Michael, and Albert Moran. 2008. "Television's New Engines." Television \& New Media 9: 155-160.

Keinonen, Heidi. 2017. "Television Format as Cultural Technology Transfer: Importing a Production Format for Daily Drama." Media, Culture \& Society 39 (7): 995-1010. https://doi.org/10.1177/0163443716682076.

Levine, Caroline. 2016. Forms: Whole, Rhythm, Hierarchy, Network. Princeton, NJ, and Oxford: Princeton University Press.

Magder, Ted. 2004. "The End of TV 101: Reality Programs, Formats, and the New Business of Television." In Reality TV: Remaking Television Culture, edited by Susan Murray and Laurie Ouellette, 137-56. New York: New York University Press.

McCarthy, Anna. 2006. "From the Ordinary to the Concrete: Cultural Studies and the Politics of Scale." In Questions of Method in Cultural Studies, edited by Mimi White and James Schwoch, 21-53. Malden, MA: Blackwell. 
McKernan, Luke. 2011. "Rituals and Records: The Films of the 1924 and 1928 Olympic Games." European Review 19 (4): 563-577. https://doi.org/10.1017/S1062798711000196.

Mikos, Lothar. 1995. "Internationale Fernsehformate Und Nationale Sehgewohnheiten.” In Kommunikationsraum Europa, edited by Lutz Erbring, 169-80. Konstanz: UVK.

Moran. 2009. New Flows in Global Television. Chicago: Chicago University Press.

Moran, Albert. 1998. Copycat TV: Globalisation, Program Formats and Cultural Identity. Luton: University of Luton Press.

Morse, Margaret. 1983. "Sport on Television: Replay and Display." In Regarding Television: Critical Approaches, edited by E. Ann Kaplan, 44-66. Los Angeles: American Film Institute.

Ouellette, Laurie, and Julie Wilson. 2011. "Women's Work." Cultural Studies 25 (4/5): 54865. https://doi.org/10.1080/09502386.2011.600546.

Radhakrishnan, Regunathan, Isao Otsuka, Ziyou Xiong, and Ajay Divakaran. 2005. "Modelling Sports Highlights Using a Time Series Clustering Framework and Model Interpretation." In Proceedings of the SPIE, 5682, Storage and Retrieval Methods and Applications for Multimedia, 269-76. https://doi.org/10.1117/12.588059.

Rampazzo Gambarato, Renira, Geane Carvalho Alzamora, Lorena Peret Teixeira Tárcia, and Amanda Chevtchouk Jurno. 2017. "2014 FIFA World Cup on the Brazilian Globo Network: A Transmedia Dynamics?" Global Media and Communication 13 (3): 283301.

Shifman, Limor. 2013. Memes in Digital Culture. Cambridge, MA: MIT Press.

"Staatsvertrag für Rundfunk und Telemedien (Rundfunkstaatsvertrag - RStV)." 2016. http://www.ard-werbung.de/fileadmin/user_upload/mediaperspektiven/Dokumentation/2016-1_Rundfunkstaatsvertrag.pdf.

Stauff, Markus. 2018a. "The Pregnant-Moment Photograph: The 1908 London Marathon and the Cross-Media Evaluation of Sport Performances." Historical Social Research 43 (2): 203-19. https://doi.org/10.12759/hsr.43.2018.2.203-219. 2018b. "Non-Fiction Transmedia: Seriality and Forensics in Media Sport." $M / C$ Journal 21 (1). http://journal.mediaculture.org.au/index.php/mcjournal/article/view/1372.

Sterne, Jonathan. 2006. "The Mp3 as Cultural Artifact" 8 (5): 825-842. https://doi.org/10.1177/1461444806067737. . 2012. MP3: The Meaning of a Format. Durham, NC: Duke University Press.

Streible, Dan. 2008. Fight Pictures: A History of Boxing and Early Cinema. Berkeley, Los Angeles, and London: University of California Press.

“Top 100 Goals Scored by Legendary Football Players." 2018. YouTube video, posted by "Notelicioux," July 17. https://www.youtube.com/watch?v=g94QgTwpXQk.

“Top 33 UNEXPECTED Goals." 2018. YouTube video, posted by "Wizzer," November 15, https://www.youtube.com/watch?v=zynSRSGp5bA.

Vogan, Travis. 2014. Keepers of the Flame: NFL Films and the Rise of Sports Media. Urbana: University of Illinois Press.

Waisbord, Silvio. 2004. "McTV: Understanding the Global Popularity of Television Formats." Television \& New Media 5 (4): 359-383. https://doi.org/10.1177/1527476404268922.

Werron, Tobias. 2009. Der Weltsport Und Sein Publikum: Zur Autonomie Und Entstehung Des Modernen Sports. 1st ed. Weilerswist: Velbrück. - 2010. "World Sport and Its Public. On Historical Relations of Modern Sport and the Media." In Observing Sport: System-Theoretical Approaches to Sport as a Social Phenomenon, edited by Ulrik Wagner and Rasmus Storm, 33-59. Schorndorf: Hofmann. 
- 2014. "On Public Forms of Competition." Cultural Studies $\leftrightarrow$ Critical Methodologies 14 (1): 62-76. https://doi.org/10.1177/1532708613507891.

Whannel, Garry. 1991. "'Grandstand', the Sports Fan and the Family Audience.” In Popular Television in Britain: Studies in Cultural History, edited by John Corner, 182-196. London: BFI.

Winkie, Luke. 2016. "The Quasi-Legal World of NBA Highlight Videos." Sports Illustrated, February 9, 2016. https://www.si.com/extra-mustard/2016/02/09/nba-highlightvideos-clips-youtube-legality.

Young, Liam Cole. 2017. List Cultures: Knowledge and Poetics from Mesopotamia to BuzzFeed. Amsterdam: Amsterdam University Press. 